\title{
CASARAVILLA: LA PRÁCTICA DE LOS SENTIDOS
}

\author{
POR \\ ROBERTO APRATTO \\ Instituto de Profesores "Artigas"
}

El tiempo de Enrique Casaravilla Lemos (Montevideo, 1889-1967) es el de la generación postmodernista, o de los veinte. Son sus coetáneos Carlos Sabat Ercasty, Vicente Basso Maglio, Emilio Oribe, Juana de Ibarbourou, Juan Parra del Riego, Fernán Silva Valdés, Pedro Leandro Ipuche, entre otros poetas de importancia. La denominación postmodernista alude - tal vez como vago intento de hacer coherente una promoción de escritores cuyo punto central es, precisamente, la diversidad de actitudes estéticas-no tanto a la condición de sucesores cronológicos cuanto a la de detractores del modernismo rubendariano y sus secuelas nacionales (las que pueden rastrearse en nuestra generación del 900 ). Es, fundamentalmente, una época de intensa actividad productiva y editorial, signada por la búsqueda de una expresión literaria propia y que aspira a liberarse de los resultados indeseables de la renovación poética modernista: la obsesividad de la rima y el metro, el exotismo, la oscuridad lexical y sintáctica.

La salida a ese estado de cosas puede verse en dos movimientos no necesariamente divergentes, y que las revistas literarias ( La Cruz del Sur, Los Nuevos, Pegaso, Teseo, Alfar, La Pluma) canalizan: uno, de apertura al mundo, que vertebra la eclosión de los vanguardismos europeos de las primeras décadas del siglo (futurismo, cubismo, dadaísmo, ultraísmo) sin toma de partido, como cuerpo de noticias a ser asumido eclécticamente; otro, de revitalización de lo nacional, de los motivos históricos y camperos, que busca su dimensión universal integrando los aportes de esos vanguardismos. Cristaliza en el nativismo de Ipuche y Silvia Valdés, pero también puede emparentarse a la llaneza expresiva y temática de Juana de Ibarbourou. Si se examina la producción poética de la época, se verá en ese doble movimiento la prevalencia del eclecticismo y la mesura: aparte de Juan Parra del Riego (de temas, aliento y actitud futuristas) la novedad integrada a la expresión nacional es exclusivamente el verso libre.

Por otra parte, dicha producción of frece un panorama tan amplio como difícil de enmarcar. Lo que Carlos Real de Azúa designaba "ausencia de una rigurosa autocrítica" $y$ "confusión entre la obra y el estado de fertilidad lírica" parecen ser los rasgos más señalables de una promoción que busca ante todo la expresión personal de maneras muy diversas de concebir la poesía. Poco hay que vincule 
entre sí el equilibrio de Casal Muñoz, la exaltación semi-mística de Sabat Ercasty, la lírica metafísica de Oribe, la musicalidad hermética de Basso Maglio, la epocalidad de Parra del Riego, la exploración criollista de Silva Valdés, la vitalidad reflexiva de Ipuche. Todo es aceptado bajo el signo de la poesía, que vive, quizás, su hora más prestigiosa en nuestra historia. En ese clima de desniveles y diferencias está también la poesía de Casaravilla Lemos.

La obra édita de Casaravilla no es extensa: cuatro libros (Celebración de la primavera, 1912; Las fuerzas ocultas, 1920; Las formas desnudas, 1930; Partituras secretas, 1967), separados entre sí por largos intervalos, alcanzan sin embargo para dar la medida de su originalidad respecto a los cánones expresivos de su tiempo. Alberto Zum Felde, Eduardo Dieste, Esther de Cáceres, y más recientemente Ida Vitale, han dado cuenta de su "rareza" esencial, reductible a la condición de "poeta y sólo poeta" (Zum Felde) y que parece confirmada por una vida semi-ascética, de confinamientos periódicos en casas de salud y ajena a toda voluntad de incidencia en la cultura literaria nacional. El propósito de este trabajo es probar esa rareza en términos de lenguaje, es decir, descubrir allí la clave de la modernidad de la poesía de Casaravilla y su carácter de modelo posible para la escritura del presente. A nuestrojuicio, el hecho, a más de veinte años de su muerte, de que esa posibilidad de ser modelo siga trunca, se debe en buena parte a juicios de recepción que mantuvieron su valor en un terreno de marginalidad: como poeta fino, profundo, inteligente, exacto, Casaravilla ha sido visto por la crítica (a excepción de Ida Vitale) como, precisamente, un "raro", intraducible dentro y fuera de su generación; alguien cuya obra sólo puede ser defendida y atesorada por poetas. Aquí, por lo tanto, conviene extraer del análisis conclusiones que extiendan su trabajo a la condición de emergente de posibilidades textuales que pueden ser comprendidas y "digeridas" ahora.

Ante todo, y situándonos en la pura empiria: ¿dónde está la singularidad de Casaravilla Lemos? El juicio de Zum Felde ("casi ninguna influencia literaria concreta podría señalarse en su obra") es exacto pero insuficiente. También lo son las precisiones acerca de sus temas y tonos expresivos (la unión de sensualidad y mística, a la que se agregaría un panteísmo muy personal). El comienzo de la respuesta podría estar en la confrontación de su poesía con la media poética de su tiempo, es decir, con aquello que, más allá de las diferencias individuales anotadas, constituye la norma expresiva del Uruguay de los veinte, y que puede denominarse ajuste entre la idea y la forma. Un ajuste o "redondeo" que determina que, en la mayoría de los casos (la obra de Basso Maglio podría ser una excepción) la poesía agote sus recursos en la presentación de la idea, clara u oscura, concreta o abstracta, y desaparezca en el parafraseo de contenidos; si a eso se agrega un estilo o surplus de elegancia en el decir, lo que convierte al discurso en lírica legítima, se obtiene un estatuto canónico de la poesía que podría aplicarse también a la producción posterior al veinte, y no sólo uruguaya.

En el caso de Casaravilla, tal ajuste no existe. Si se toman en cuenta sus dos últimos libros, Las formas desnudas y Partituras secretas, puede verse la exacerbación de un modo enunciativo que no sólo trasciende los temas elegidos 
(lo cual, como veremos, es pasible de una disquisición adicional) sino que es objeto de una modulación de posibilidades tan múltiples como sorprendentes y enriquecedoras del texto. Es entonces la enunciación, el acto en que se produce el enunciado, lo que puede servir de base para apreciar las cualidades específicas de su poesía. Debe destacarse, con toda su fuerza de presente, esa condición de acto, de proceso mostrado en bruto, de movimiento puro, que el trabajo de Casaravilla actualiza; es algo así como un paso sobre el mensaje que llama la atención sobre sí mismo y determina el modo de la recepción. Vayamos a ejemplos, aunque el fenómeno es inagotable.

La enunciación puede ser entrecortada, con cortes, pausas, elipsis o estiramientos nacidos del mismo proceso del texto:

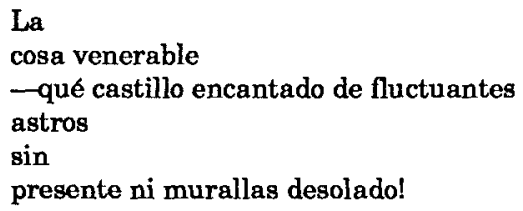

( La cosa que vemos)

o

Reina, flor ninguna la

nada. Ningún asunto que llegue a importar se

ve, porque ninguno hay.

Ni brillo del sol; la negrura de

la noche; la serpiente - una nueva hoja, el mundo: apariencias.

\section{(Carta matutina)}

También bifurcarse, con desvíos, interpolaciones, acotaciones, agregados, que desplazan el peso semántico del enunciado hasta dispersarlo:

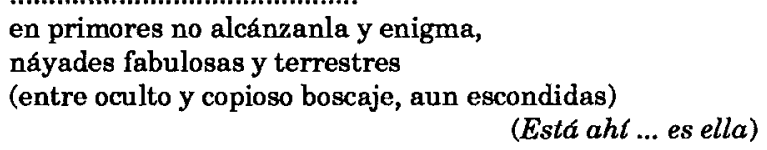

Cuando falten los estribos y no pueda subir al caballo alto y oscuro (muy alto y muy oscuro) 


\author{
que lo va a salvar \\ que conduciéndolo, lo llevará \\ ¡Qué gemidos, entonces!
}

(El rico después de la muerte)

o multitonal, cuando las exlamaciones, los giros inesperados, atraen bloques semánticos ajenos al hilo discursivo:

\author{
La cara augustamente \\ constelada! \\ De España \\ tiene; con una gracia de la patria; \\ y de la selva absurda \\ fúlgido (de este lado del Océano) \\ lánguida que entrelaza \\ (Presencia radiosa)
}

Dentro de este esquema caben también el uso de recursos espaciales (los encabalgamientos bruscos, el uso del blanco y del paréntesis) y sonoros (la redundancia, la rima como factor dominante) que crean un ritmo y una densidad propias de la escritura:
Es una hora más larga ...!
abrázate a mis brazos flor nocturna.
Nada se ve como tu vida; nada
se ve como tu dicha; flor nocturna.
Ningún misterio iguálate, ninguna
carne como la tuya; flor nocturna
blanca y lacia: en tu intensa forma se unen
mujer y flor nocturna.

(iNocturna!)

Como en un trabajo respiratorio, la omisión general de nexos y la dispersión de signos en función de impulsos expresivos produce un movimiento autónomo de la forma.

La consecuencia inmediata de esa múltiple apertura enunciativa es la liberación del verosímil semántico y sintáctico, o sea: la ambigüedad del enunciado. Un poema de Casaravilla, casi cualquiera (más allá de los distintos niveles de radicalidad) presenta simultáneamente dos informaciones: el de una idea o un fragmento de realidad presentados "en bruto", a modo de instantánea en que coexisten ángulos en tonos diversos, y el movimiento del trabajo formal que condiciona su lectura. La producción del sentido depende, por una cuestión de acentos, de esa última vía, lo cual hace difícil (e innecesario) determinar la presencia de un yo estructurador que jerarquice niveles de alusión en el enunciado: lo trasmitido se hace ambiguo en razón de ese asedio múltiple; el 
poema entero se hace extraño, sorprendente ( $\mathrm{o}$ "raro") por la conmixtión de esa ambigủedad (no de significados sino de referentes) y la claridad, a veces ingenua, resultante de la restricción de convenciones connotativas, de un "animarse" a transparentar el impulso de decir con que la forma se impone.

De esa claridad deriva, por otra parte, la concreción, el "volumen entitativo casi irresistible" (Real de Azúa) de seres, objetos y lugares, a modo de lecturas sintéticas de la realidad que escapan del orden predicativo para obligar a ser vistas por sí mismas. Son, por así decirlo, engrosamientos del hilo discursivo que éste prevé en tanto encadenamiento o diálogo interno de ímpetus designativos. Es así como la sensualidad (elemento varias veces reconocido como constante en la poesía de Casaravilla) deja de ser una información ajena, previa al texto, para convertirse en forma, en línea de fuerza que arrastra contextos diferentes y es mostrada (como entusiasmo de los sentidos) al mismo tiempo que la manipulación enunciativa que la articula. Por otra parte, la noción de diálogo interno es esencial para comprender esa apertura y entrecruzamiento de niveles de habla con que el texto "perfora" su univocidad. Esa interacción incluye a los géneros cuando la liberación discursiva se desplaza del verso a la prosa (por acumulación o desborde).

Parece claro, a esta altura, que toda revisión de la obra de Casaravilla debe dejar constancia de un dato inexcusable: el de la presencia, en acción, a un nivel y con una regularidad poco frecuentes, de conciencia textual: conciencia sonora, espacial, metalingüistica, distributiva, selectiva, que endurece el trabajo (precisamente a favor de su flexibilidad) para proyectarlo más allá de su tiempo y del Uruguay. Lo moderno en su poesía, por eso, soporta el peso del envejecimiento o la ingenuidad cursi de sus temas (lo angélico, lo panteísta). La suya es un ejemplo de cómouna escritura puede traspasar su contexto productivo (valores, cosmovisión, ideas sobre poesía) y hacerse sincrónica con una lectura posterior (la nuestra, en este caso). El recurso es, simplemente, ser otra cosa que lo que se dice.

Finalmente: la condición de modelo para la creación actual no puede separarse de una noción de valor. Casaravilla es un poeta de quien se puede aprender no sóloel uso de procedimientos formales, ni la resolución de problemas prácticos de sintaxis y significado, sino una actitud crítica ante el material verbal recibido que induce una similar en sus lectores y lo separa netamente de sus contemporáneos. Escribir, para él (como para Julio Herrera y Reissig, como para Juan Cunha, como para muy pocos más en nuestra historia literaria) es la búsqueda de una zona de realidad propia del lenguaje, intraducible a otro campo, y que consiste en una experimentación con posibilidades que lo alejan de la comunicación y la simbolización convencionales. Esa "otra cosa" que propone Casaravilla, esa realidad tan permanente como el movimiento (o agitación) formal que sus textos hacen visibles, lo convierte en uno de los pocos poetas uruguayos de verdadera importancia. $\mathrm{O}$, lo que es lo mismo: que tiene futuro. 


\section{BIBLIOGRAFIA CONSULTADA}

Cáceres, Esther de, Prólogo a Partituras secretas (Montevideo: Ministerio de Instrucción Pública, 1967).

Mignolo, Walter, Semantización de la ficción literaria (Ann Arbor: Department of Romance Languages, University of Michigan, 1980).

Real de Azúa, Carlos: Un siglo y medio de literatura uruguaya (Montevideo: Ediciones de la Universidad,1958).

Vitale, Ida, Los poetas del veinte. Capítulo Oriental 21 (Montevideo, 1968). Enrique Casaravilla Lemos. Material de lectura, Serie Poesía Moderna 106 (México, 1984).

Zum Felde, Alberto, Proceso intelectual del Uruguay (Montevideo: Imprenta Nacional Colorada, 1930). 